\title{
Antimicrobial Activity of Cetylpyridinium Chloride against Listeria monocytogenes on Frankfurters and Subsequent Effect on Quality Attributes ${ }^{\dagger}$
}

\author{
M. SINGH, V. S. GILL, H. THIPPAREDDI, $\ddagger$ R. K. PHEBUS,* J. L. MARSDEN, T. J. HERALD, AND A. L. NUTSCH \\ Department of Animal Sciences \& Industry and the Food Science Institute, Kansas State University, Manhattan, Kansas 66506, USA
}

MS 04-572: Received 15 December 2004/Accepted 15 April 2005

\begin{abstract}
Frankfurters inoculated with Listeria monocytogenes were treated with $1 \%$ cetylpyridinium chloride (CPC) or with $1 \%$ CPC followed by a water rinse at various combinations of spray temperatures $\left(25,40\right.$, and $\left.55^{\circ} \mathrm{C}\right)$, spray pressures $(20,25$, and $35 \mathrm{psi})$, and times of exposure (30,40, and $60 \mathrm{~s})$. No significant differences $(P>0.05)$ were observed in the reductions achieved by $1 \%$ CPC + water wash and those achieved with $1 \%$ CPC treatment alone. L. monocytogenes populations were reduced by ca. $1.7 \log \mathrm{CFU} / \mathrm{g}$ immediately following treatment, with no differences $(P>0.05)$ observed for different spray temperatures, pressures, or exposure times. The effectiveness of $1 \% \mathrm{CPC}$ spray treatment (at $25^{\circ} \mathrm{C}, 20 \mathrm{psi}$, and $30 \mathrm{~s}$ of exposure) against $L$. monocytogenes on vacuum-packaged frankfurters stored at 0 and $4^{\circ} \mathrm{C}$ for 42 days was then evaluated. Application of a $1 \%$ CPC surface spray to frankfurters immediately prior to packaging reduced $L$. monocytogenes concentrations by 1.4 to $1.7 \mathrm{log} \mathrm{CFU} / \mathrm{g}$ and further restricted growth of the pathogen during 42 days of refrigerated storage, thereby meeting U.S. Department of Agriculture alternatives 1 and 2 criteria for Listeria control. CPC treatment reduced aerobic plate counts, lactic acid bacteria, yeasts and molds, total coliforms, and Escherichia coli populations on noninoculated frankfurters to below detectable limits. The $1 \%$ CPC treatment did not affect the color $\left(\mathrm{L}^{*}, \mathrm{a}^{*}\right.$, and $\mathrm{b}^{*}$ values) of frankfurters stored for 42 days at 0 or $4^{\circ} \mathrm{C}(P>0.05)$. The effect of $1 \% \mathrm{CPC}$ treatment on the firmness of frankfurters was also negligible.
\end{abstract}

Listeria monocytogenes is recognized as an important cause of foodborne illness, with high hospitalization rates $(88 \%)$ and fatality rates $(20 \%)(5,16)$. Although optimal growth occurs between 30 and $37^{\circ} \mathrm{C}$, Listeria species are capable of growth over a temperature range of 1 to $45^{\circ} \mathrm{C}$, making the organism a potential food safety concern in refrigerated foods (15). Although initial outbreaks of listeriosis were linked to consumption of coleslaw, raw vegetables, milk, and Mexican-style cheese, the consumption of frankfurters has been strongly linked epidemiologically to an increased risk of listeriosis (21). In 2002, an outbreak of $L$. monocytogenes infection in eight states with 46 culture-confirmed cases, seven deaths, and three stillbirths or miscarriages was linked to turkey deli meat (7). This outbreak led to a recall involving 27.4 million pounds (12.44 $\times 10^{6} \mathrm{~kg}$ ) of fresh and frozen ready-to-eat (RTE) turkey and chicken products. Another multistate outbreak of $L$. monocytogenes (serotype 4b) linked to hotdogs involved 40 illnesses and four deaths, including one fetus and three elderly persons (6).

The U.S. Department of Agriculture Food Safety and Inspection Service (USDA FSIS) defines hot dog-type products as medium risk, in the absence of formulation,

\footnotetext{
* Author for correspondence. Tel: 785-532-1215; Fax: 785-532-5681; E-mail: phebus@ksu.edu.

$\dagger$ This is contribution 05-125-J from the Kansas Agricultural Experiment Station, Manhattan.

$\ddagger$ Present address: Department of Food Science and Technology, University of Nebraska, Lincoln, NE 68583, USA.
}

production, or distribution processes validated to prevent the growth of L. monocytogenes (24). In terms of the relative risk of foodborne listeriosis from RTE products, frankfurters (nonreheated) have been classified as very high risk "reflecting the fact that they have relatively high rates of contamination, support the relatively rapid growth of $L$. monocytogenes under refrigerated storage, are stored for extended periods, and are consumed extensively" (30). Trends in the food industry have been toward convenient refrigerated foods with extended shelf life, and consumer concerns about cholesterol, saturated fat, total calories, and salt content have prompted food processors to modify product formulations to satisfy the demands of health-conscious consumers. Although such foods may be readily accepted and greatly appreciated by consumers, these changes in processing techniques and ingredients may have contributed to a higher prevalence and survival rate of $L$. monocytogenes in RTE meat products (2).

Various antimicrobials, including organic acids, bioactive preservatives, and bacteriocins, have been evaluated for the control of L. monocytogenes in RTE meats. Organic acids and their salts, including potassium lactate, sodium diacetate, and sodium lactate, and other compounds such as trisodium phosphate have been approved for use in the manufacture of RTE meat products (26). The application of certain generally-recognized-as-safe agents such as sodium benzoate, sodium propionate, potassium sorbate, and sodium diacetate can reduce or inhibit populations of $L$. monocytogenes (13). Palumbo and Williams (19) suggested the 
application of either acetic or lactic acid could provide additional safety for frankfurters and reduce the risk of $L$. monocytogenes contamination during peeling and packaging operations. Both bactericidal and bacteriostatic effects have been observed depending on the concentration of organic acid used as a secondary lethal step to destroy $L$. monocytogenes (19).

Recent FSIS regulations require processors to incorporate strategies to control L. monocytogenes in RTE meat products. Preferred control measures include postlethality treatments (e.g., steam pasteurization, hot water pasteurization, radiant heating, and high-pressure processing) and/ or treatment with antimicrobials or growth inhibitors (25). More research is needed to explore and evaluate additional postlethality treatments and antimicrobials. Cetylpyridinium chloride (CPC), a quaternary ammonium compound used as an active ingredient in some mouthwashes, has been approved by the U.S. Food and Drug Administration and the USDA for application to raw poultry products $(27,31)$. It is effective against foodborne pathogens such as Escherichia coli 0157:H7, Salmonella, and Listeria spp. in a variety of food matrices including poultry skin $(3,4,33,34)$, fresh beef tissue (10), and fresh-cut vegetables (32).

The objectives of this study were to examine the efficacy of $1 \%$ CPC as a postprocess decontaminant for RTE meats, to optimize spray treatment application parameters for reducing populations of $L$. monocytogenes on frankfurters, to determine the effects of these treatments on $L$. monocytogenes outgrowth during chilled product storage, and to evaluate the subsequent impact on quality attributes (color and firmness) of frankfurters.

\section{MATERIALS AND METHODS}

Preparation of bacterial cultures. A five-strain cocktail of L. monocytogenes (serotype 3, ATCC 19113; serotype 4c, ATCC 19116; and strains 101M, 109, and 108M obtained from Dr. Larry Beuchat, University of Georgia, Griffin) was used for inoculation of frankfurters. Cultures were maintained separately on slants of tryptic soy agar (Difco, Becton Dickinson, Sparks, Md.) at $4^{\circ} \mathrm{C}$. Each culture was inoculated individually into $10 \mathrm{ml}$ of tryptic soy broth (TSB; Difco, Becton Dickinson) and incubated at $35^{\circ} \mathrm{C}$ for $24 \mathrm{~h}$. Aliquots $(1 \mathrm{ml})$ were then transferred individually into 100 $\mathrm{ml}$ of TSB and incubated at $35^{\circ} \mathrm{C}$ for $20 \mathrm{~h}$. Each culture was centrifuged at $15,600 \times g$ for $10 \mathrm{~min}$ at $4^{\circ} \mathrm{C}(\mathrm{J} 2-21 \mathrm{M} / \mathrm{E}$ centrifuge and JA-14 rotor, Beckman, Palo Alto, Calif.), and the cell pellets were each resuspended in $50 \mathrm{ml}$ of sterile $0.1 \%$ peptone diluent (Difco, Becton Dickinson). Cultures were then recentrifuged, and the resultant pellets were each resuspended in $10 \mathrm{ml}$ of $0.1 \%$ peptone diluent. A cocktail was prepared by combining the five cultures to obtain a final volume of $50 \mathrm{ml}$ of inoculum; this mixed culture was designated the high-concentration inoculum. To prepare a low-concentration inoculum, a portion of the original cocktail was diluted by a factor of 10,000. The high- and low-concentration inoculum suspensions were each placed in high-density polyethylene spray bottles (Sprayco, Detroit, Mich.) for use in the mist inoculation procedure.

Inoculation of frankfurter surfaces. Frankfurters (all beef, eight per pack) were obtained from a commercial meat processor and stored at $4{ }^{\circ} \mathrm{C}$. All frankfurters were obtained from the same manufacturer, and the frankfurters within a replicate experiment were from the same lot. Prior to inoculation, frankfurters were removed from packages and placed onto butcher paper. Each frankfurter was individually dried using blotting paper. To avoid contamination during handling, one end of each frankfurter was wrapped with 2-inch (5-cm)-wide parafilm (Laboratory film, American National Can, Chicago, Ill.). The inoculum cocktail was misted onto the frankfurters in a specially constructed biocontainment chamber (Kansas State University, Manhattan, Kans.) to achieve either a high ( 7 to $8 \log \mathrm{CFU} / \mathrm{g}$ ) or low (2 to $3 \log \mathrm{CFU} /$ g) level of L. monocytogenes contamination. After inoculation, the frankfurters were held at $25^{\circ} \mathrm{C}$ for $30 \mathrm{~min}$ in a laminar flow cabinet (SterilGARD II, The Baker Company, Sanford, Maine) to allow attachment of $L$. monocytogenes onto the surface of the product. Samples used for evaluating effects on naturally occurring microbial populations, color, and firmness were not inoculated.

CPC treatments. A 1\% solution of CPC (CECURE, Safe Foods Corporation, North Little Rock, Ark.) was prepared by adding $25 \mathrm{ml}$ of $40 \%$ concentrated $\mathrm{CPC}$ to $1,000 \mathrm{ml}$ of deionized water at $25^{\circ} \mathrm{C}$. The average $\mathrm{pH}$ of the $1 \% \mathrm{CPC}$ solution, determined using a pH meter (model SA 520, Orion Research Inc., Beverly, Mass.), was 7.0. The CPC spray wash treatments were applied to frankfurter samples using a flat jet type spray nozzle in a laboratory model spray washer (Kansas State University). Frankfurters were placed $6.5 \mathrm{~cm}$ from the nozzles.

To determine the effect of spray application parameters, frankfurters inoculated at a high initial concentration were treated with $1 \% \mathrm{CPC}$ or $1 \% \mathrm{CPC}$ followed by a $25^{\circ} \mathrm{C}$ water wash $(1 \%$ $\mathrm{CPC}+$ water wash). Three frankfurters were assigned to each treatment combination of spray temperature $\left(25,40\right.$, or $\left.55^{\circ} \mathrm{C}\right)$, spray pressure $(20,25$, or $35 \mathrm{psi})$, and time of exposure to $\mathrm{CPC}$ $(30,40$, or $60 \mathrm{~s})$. Both $1 \% \mathrm{CPC}$ and $1 \% \mathrm{CPC}+$ water wash were evaluated for each set of parameter combinations.

To determine the effectiveness of a $1 \%$ CPC solution for controlling the outgrowth of L. monocytogenes during refrigerated storage, frankfurters inoculated at either a high or low concentration were sprayed with $1 \% \mathrm{CPC}$ at $20 \mathrm{psi}$ and $25^{\circ} \mathrm{C}$ with a $30-\mathrm{s}$ time of exposure (spray washer delivered $1.6 \mathrm{~L} / \mathrm{min}$ at $20 \mathrm{psi}$ ). Both CPC-treated and nontreated (control) inoculated samples were then vacuum packaged (Multivac, Kansas City, Mo.) in sets of three samples per package ( 8 by 10 in. [20 by $25 \mathrm{~cm}$ ], 3 mil standard barrier, nylon/PE vacuum pouch), and packages were stored at both 0 and $4^{\circ} \mathrm{C}$ for up to 42 days. The effect of CPC treatment on naturally occurring bacterial populations, color, and firmness were determined using noninoculated samples (same treatment parameters as inoculated samples: 1\% CPC, $20 \mathrm{psi}$, $25^{\circ} \mathrm{C}$, and 30 -s exposure). Noninoculated frankfurters (treated and nontreated) were vacuum packaged in sets of four as described above and stored for up to 42 days at $0^{\circ} \mathrm{C}$ in a walk-in cooler (dark) or at $4^{\circ} \mathrm{C}$ in a retail display cabinet. Microbiological populations, color, and firmness were evaluated on days $0,3,7,14$, 21,28 , and 42 .

Sample collection and microbiological analysis. To determine populations of L. monocytogenes, two frankfurters from the set of three comprising a sample were used for direct plating, and the remaining frankfurter was held in refrigerated storage for use in subsequent enrichment procedures in the event that no L. monocytogenes were recovered by direct plating. The two frankfurters used for direct plating were placed in a sterile stomacher bag and homogenized for $2 \mathrm{~min}$ with $100 \mathrm{ml}$ of $0.1 \%$ peptone diluent in a stomacher (Tekmar Co., Cincinnati, Ohio).

Serial dilutions were prepared in $0.1 \%$ peptone diluent, and appropriate dilutions were plated onto modified Oxford agar (MOX; Oxoid Ltd., Basingstoke, Hampshire, UK) and tryptose 
phosphate agar (TPA; Difco, Becton Dickinson) using an automatic spiral plater (Don Whitley Scientific Ltd., Shipley, West Yorkshire, UK). Plates were incubated at $37^{\circ} \mathrm{C}$ for $24 \mathrm{~h}$, and typical colonies were enumerated manually using a spiral plate darkfield Quebec colony counter (model 330, American Optical Company, Buffalo, N.Y.). Counts were recorded as log CFU per gram. Five typical L. monocytogenes colonies from duplicate plates on MOX and TPA were isolated and confirmed as L. monocytogenes using Gram staining procedures and a primary catalase test. Isolates were further confirmed by testing for fermentation of glucose, xylose, and mannitol and reduction of nitrite. The presence or absence of L. monocytogenes in samples inoculated at low concentration (2 to $2.5 \mathrm{log} \mathrm{CFU} / \mathrm{g}$ ) was determined by Listeria enrichment procedures (29). Modified Listeria enrichment broth (Difco, Becton Dickinson) was incubated at $35^{\circ} \mathrm{C}$ for 24 to $48 \mathrm{~h}$ and then streaked onto MOX. The MOX plates were incubated at $35^{\circ} \mathrm{C}$ for 24 to $48 \mathrm{~h}$, and colonies typical of L. monocytogenes were confirmed as described.

To evaluate the naturally occurring bacterial populations over storage time, one frankfurter from the set of four noninoculated frankfurters in a sample was used for microbiological analysis and one each was used for evaluation of color and texture. The one frankfurter used for microbiological analysis was homogenized with $100 \mathrm{ml}$ of $0.1 \%$ peptone diluent in a stomacher for $2 \mathrm{~min}$, and serial dilutions were prepared in $0.1 \%$ peptone diluent. Samples were analyzed for aerobic plate counts (APCs), total coliform counts, Escherichia coli counts, yeast and mold (YM) counts, and lactic acid bacteria (LAB) counts.

Appropriate serial dilutions were plated on APC Petrifilm (3M, St. Paul, Minn.) to determine APCs and on ECC Petrifilm (3M) to determine E. coli and total coliform counts. The APC and ECC Petrifilm were incubated at $35^{\circ} \mathrm{C}$ for 24 to $48 \mathrm{~h}$. Potato dextrose agar containing $100 \mathrm{ppm}$ chloramphenicol (PDA; Difco, Becton Dickinson) and deMan Rogosa Sharpe agar (MRS; Difco, Becton Dickinson) were used to determine YM and LAB populations, respectively. PDA was incubated at room temperature $\left(25^{\circ} \mathrm{C}\right)$ for $48 \mathrm{~h}$, and MRS was incubated anaerobically at $35^{\circ} \mathrm{C}$ for 24 to $48 \mathrm{~h}$ in an anaerobe jar with an anaerobic system envelope (GasPak Plus, Becton Dickinson).

Color attributes. Color evaluations were performed using a Hunter D54 spectrophotometer (Ultra Scan SpecWare, version 1.20, Hunter Associates Laboratories, Reston, Va.) with a $10^{\circ} \mathrm{ob}-$ server angle and A illuminate to determine the $\mathrm{L}^{*}$ (lightness), $\mathrm{a}^{*}$ (redness), and $\mathrm{b}^{*}$ (yellowness) of frankfurters. The instrument was standardized with black and white tiles. Samples stored at $4^{\circ} \mathrm{C}$ were held in a display case that simulated retail store lighting conditions, whereas samples stored at $0^{\circ} \mathrm{C}$ were held in a cooler with no lighting. Within the $4^{\circ} \mathrm{C}$ display case, the light intensity was maintained at 1,070 lux (107 foot candles) using deluxe warm white fluorescent light and was measured at weekly intervals with a light meter (model 407026, Extech Instruments Corp., Waltham, Mass.). Samples were rotated and turned over at 3-day intervals for proper distribution of light on the surface of the samples.

Texture attributes. A texture analyzer (TA-XT2, Stable Micro Systems, Haslemere, UK) was used to determine the firmness of frankfurters. Frankfurters were removed from 0 and $4^{\circ} \mathrm{C}$ storage and tempered at room temperature for $30 \mathrm{~min}$. A 2.54-cm segment was precisely cut from the middle of each sample and placed vertically on the TA-XT2 TA-90 platform. A p-75 compression probe with $100-\mathrm{g}$ force and a $5-\mathrm{kg}$ load cell was used at $2.0 \mathrm{~mm} /$ $\mathrm{s}$ pretest and $5.0 \mathrm{~mm} / \mathrm{s}$ posttest. The samples were compressed to $35 \%$ of their height. The auto trigger feature was set at $5.0 \mathrm{~g}$. Data were collected at 200 points per s.
Experimental design and statistical analysis. A randomized block design of three temperatures, three spray pressures, and three exposure times was used to evaluate the efficacy of $1 \% \mathrm{CPC}$ or $1 \% \mathrm{CPC}+$ water wash for reducing L. monocytogenes on surfaces of RTE meat products. Three replicates of the experiment were performed. Data were analyzed using a three-way analysis of variance (ANOVA) from the SAS PROC GLM procedure (1998, SAS Institute, Cary, N.C.).

A similar design was used to evaluate the efficacy of $1 \%$ CPC to inhibit growth of L. monocytogenes, aerobic bacteria, $\mathrm{LAB}$, E. coli, total coliforms, and YM and to determine the effects of treatment on color and firmness of frankfurters stored at 0 and $4^{\circ} \mathrm{C}$ with repeated measures on days $0,3,7,14,21,28$, and 42 . Experiments were performed in triplicate, and an ANOVA was performed using the PROC MIXED procedure and comparison of the LSmeans (SAS Institute).

\section{RESULTS AND DISCUSSION}

Effects of spray temperature, spray pressure, and time of exposure to $1 \%$ CPC on destruction of $L$. monocytogenes. Regardless of spray pressure or time of CPC exposure, populations of $L$. monocytogenes were reduced by $1.58,1.60$, and $1.38 \log \mathrm{CFU} / \mathrm{g}$ following treatment with $1 \% \mathrm{CPC}$ at temperatures of 25,40 , and $55^{\circ} \mathrm{C}$, respectively (Fig. 1). Treatment effectiveness was not improved $(P>$ $0.05)$ by increasing the spray pressure from 20 to 35 psi, extending the time of CPC exposure from 30 to $60 \mathrm{~s}$, or increasing the spray temperature from 25 to $55^{\circ} \mathrm{C}$ (data for spray pressures and exposure times not shown). Reductions achieved by $1 \% \mathrm{CPC}+$ water wash were not significantly different $(P>0.05)$ from those of CPC treatment alone (Fig. 1). L. monocytogenes populations on frankfurters following treatment with $1 \% \mathrm{CPC}$ or $1 \% \mathrm{CPC}+$ water wash were similar $(P>0.05)$ on both selective (MOX) and nonselective (TPA) media (data not shown), indicating an absence of sublethally injured cells.

In evaluating CPC as an antimicrobial treatment, other researchers also have noted no improvement in efficacy with increased pressure or exposure time. Breen et al. (4) used CPC spray treatments to reduce Salmonella populations on chicken skin, and at CPC concentrations of $2 \mathrm{mg} /$ $\mathrm{ml}$ or less, reductions were similar for both 1- and 3-min exposure times. Wang et al. (33) evaluated a $0.1 \% \mathrm{CPC}$ spray (30-s exposure time) for reducing Salmonella on chicken skin at three application temperatures $(10,35$, and $60^{\circ} \mathrm{C}$ ) and five pressures (from 30 to $150 \mathrm{psi}$ ). The role of spray pressure on treatment effectiveness was reported as negligible at low application temperatures but critical at high application temperatures. The authors also noted the formation of foam when CPC solutions were prepared at warm or hot temperatures and speculated that the foam may have negatively impacted bactericidal effectiveness. In our study, formation of foam was also observed at higher temperatures and pressures.

Because efficacy was not improved at increasing spray pressure, temperature, or exposure time (within the ranges evaluated in this study), application parameters of $25^{\circ} \mathrm{C}, 20$ psi, and 30-s exposure time were selected to evaluate the effectiveness of $1 \% \mathrm{CPC}$ treatment for controlling the outgrowth of L. monocytogenes on frankfurters during refrig- 
FIGURE 1. Mean L. monocytogenes populations (recovered on MOX) on frankfurters inoculated at ca. $8.2 \mathrm{log} \mathrm{CFU} / \mathrm{g}$ and treated with either (ם) $1 \%$ cetylpyridinium chloride $(C P C)$ spray at three temperatures or $(\square) 1 \%$ CPC spray followed by $25^{\circ} \mathrm{C}$ water wash. Means represent pooled data for spray pressures (20, 25, and 35 psi) and CPC exposure times (30, 40, and $60 \mathrm{~s})$. Means with different letters are significantly different $(\mathrm{P} \leq 0.05)$. Error bars indicate standard deviation of the mean of three replicates.

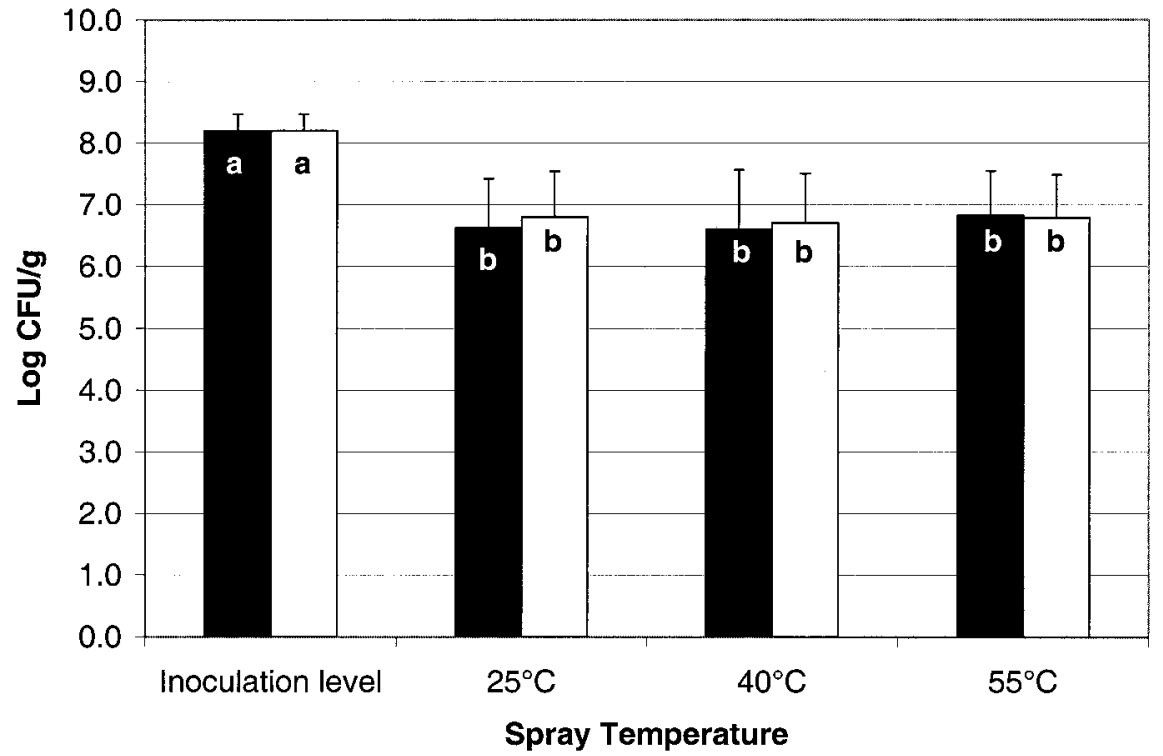

erated storage and for determining the effect on naturally occurring microbial populations, color, and texture of noninoculated frankfurters.

Effectiveness of 1\% CPC for controlling outgrowth of $L$. monocytogenes on frankfurters during refrigerated storage. L. monocytogenes populations on control and CPC-treated frankfurters during refrigerated storage are shown in Figure 2. At both low and high inoculation concentrations, ANOVA results indicated that a combination of treatment and day had a significant effect $(P \leq 0.05)$ on the recovery of $L$. monocytogenes from frankfurters. For both inoculation concentrations, regardless of storage temperature, L. monocytogenes populations on CPC-treated samples were significantly lower $(P \leq 0.05)$ than populations on control samples on each sampling day. Storage temperature appeared to have negligible impact; within each sampling day L. monocytogenes populations on control samples stored at 0 and $4^{\circ} \mathrm{C}$ were not significantly different. Similarly, within each sampling day populations on CPC-treated samples stored at 0 and $4^{\circ} \mathrm{C}$ were not significantly different (Figs. 2A and 2B).

At the low inoculation concentration (Fig. 2A), immediately following CPC spray treatment L. monocytogenes populations were reduced by $1.4 \log \mathrm{CFU} / \mathrm{g}$. Populations on CPC-treated samples remained $\leq 1.5 \mathrm{log} \mathrm{CFU} / \mathrm{g}$ through 14 days of storage; at 42 days of storage populations on CPC-treated samples were approximately $2.0 \mathrm{log}$ CFU/g. L. monocytogenes populations on control samples remained relatively constant at about 2.0 to $2.5 \mathrm{log}$ CFU/g through the first 7 days of storage, after which they gradually increased to a final population of 4.5 to $5.0 \log$ CFU/ g by day 42 (Fig. 2A). During the first 28 days of storage, L. monocytogenes populations on CPC-treated samples were 1.4 to $1.8 \log \mathrm{CFU} / \mathrm{g}$ lower $(P \leq 0.05)$ than those of controls; by day 42 of storage, populations on CPC-treated samples were 2.6 to $3.0 \mathrm{log} \mathrm{CFU} / \mathrm{g}$ lower $(P \leq 0.05)$ than those of controls. Overall, from day 0 to day 42 of storage L. monocytogenes populations of CPC-treated samples increased by 0.8 and $1.2 \log$ cycles at 0 and $4^{\circ} \mathrm{C}$, respectively, whereas over the same storage period populations of nontreated (control) samples increased by 2.1 and 2.8 log cycles at 0 and $4^{\circ} \mathrm{C}$, respectively (Fig. 2A).

At the high inoculation concentration (Fig. 2B), immediately after CPC treatment $L$. monocytogenes populations were reduced by $1.7 \log \mathrm{CFU} / \mathrm{g}$, after which populations of both CPC-treated and control samples remained relatively constant, with overall increases throughout storage of $<1.0 \log \mathrm{CFU} / \mathrm{g}$ for both treatments. Throughout the 42-day storage period, L. monocytogenes populations of CPC-treated samples remained 1.3 to $2.1 \log \mathrm{CFU} / \mathrm{g}$ lower $(P \leq 0.05)$ than those of control samples (Fig. 2B).

The 1\% CPC treatment had an initial bactericidal effect at both inoculation concentrations (Figs. 2A and 2B) and a bacteriostatic effect at the low concentration (Fig. 2A), which more closely represents typical contamination levels for commercially processed RTE products. This finding suggests improved microbiological safety associated with CPC-treated frankfurters during extended storage. Studies by Glass and Doyle (12) revealed that substantial growth of L. monocytogenes (approximately $3 \mathrm{log} \mathrm{CFU} / \mathrm{g}$ in 6 weeks) occurred in frankfurters at refrigeration temperatures of $4.4^{\circ} \mathrm{C}$ that had been inoculated at a concentration comparable to the low concentration used in the current study. In our study, at the low inculation concentration nontreated control samples stored at $4^{\circ} \mathrm{C}$ had a similar level of outgrowth $(2.8 \log \mathrm{CFU} / \mathrm{g})$ during a storage period of the same duration. The 1\% CPC treatment slowed the outgrowth of low concentrations of $L$. monocytogenes such that at the end of the 42-day storage period, populations of treated samples were $3.0 \mathrm{log} \mathrm{CFU} / \mathrm{g}$ lower than those of the nontreated controls.

Singh et al. (22) reported that treatment of L. monocytogenes-inoculated RTE polish sausages with a $1 \%$ CPC spray (30-s exposure) resulted in immediate reductions of 1 to $3 \log \mathrm{CFU} / \mathrm{g}$. After 42 days of $4^{\circ} \mathrm{C}$ storage, L. monocytogenes populations of treated samples were 2 to $4 \log$ $\mathrm{CFU} / \mathrm{g}$ lower than those of nontreated controls.

In evaluating surface application of antimicrobials for 

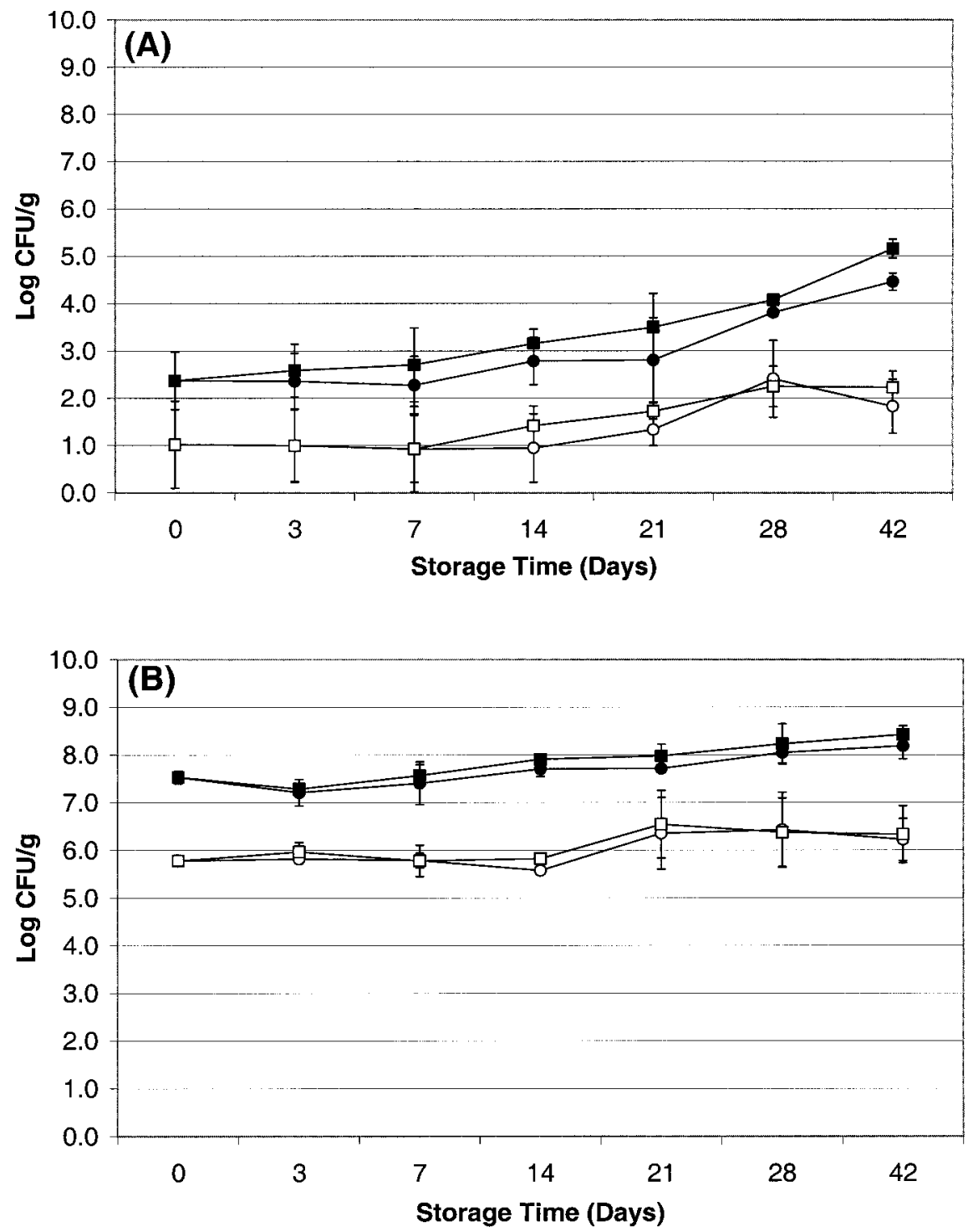

FIGURE 2. L. monocytogenes populations on frankfurters inoculated at (A) low (ca. $2.5 \log \mathrm{CFU} / \mathrm{g}$ ) and (B) high (ca. $7.5 \mathrm{log}$ CFU/g) initial concentrations and either not treated (control) or treated with cetylpyridinium chloride (1\% spray at 20 psi, $25^{\circ} \mathrm{C}$, and 30-s exposure time) and stored vacuum packaged for 42 days at 0 and $4{ }^{\circ} \mathrm{C}$. $\bigcirc$, control $0^{\circ} \mathrm{C} ; \mathbf{\square}$, control $4{ }^{\circ} \mathrm{C}$; $\bigcirc$, treatment $0^{\circ} \mathrm{C} ; \square$, treatment $4^{\circ} \mathrm{C}$. Error bars indicate standard deviation of the mean of three replicates. control of L. monocytogenes populations on frankfurters, researchers have observed initial bactericidal effects with typical reductions of approximately 0.5 to $2.0 \mathrm{log}$ cycles for antimicrobials such as organic acids $(1,19)$, organic acid salts (13), and pediocin (8). These findings are similar to the initial reductions observed following CPC treatment in our study. Although Barmpalia (1) found an initial bactericidal effect of $2.5 \%$ lactic or acetic acid dips, subsequent outgrowth to approximately $8 \log \mathrm{CFU} / \mathrm{cm}^{2}$ occurred on frankfurters after 40 days of refrigerated storage. Researchers have observed $L$. monocytogenes populations on pediocin-treated frankfurters that were approximately 1 to 1.5 log cycles lower than those of nontreated controls following extended refrigerated storage $(8,23)$.

The USDA interim final rule (9 CFR 430) (25) affords processors of RTE meat and poultry products three alternative approaches to control L. monocytogenes. Under alternative 1 , a postlethality treatment must be applied along with an antilisterial agent or process that prevents L. monocytogenes outgrowth throughout the product's shelf life. Alternative 2 allows an establishment to choose application of a postlethality treatment or an antimicrobial agent or pro- cess. Control of L. monocytogenes under alternative 3 would be accomplished through strict facility sanitation procedures alone. The rigor of an establishment's L. monocytogenes control program, therefore, decreases from alternative 1 to alternative 3 . In an accompanying guidance document (28), the expected levels of control for postlethality treatments and antimicrobial agents or processes are defined. A postlethality treatment must achieve $\geq 1 \log$ cycle reduction of $L$. monocytogenes, and products manufactured using treatments achieving 2 log cycle reductions would be sampled relatively less frequently in the USDA regulatory program. To be considered an antimicrobial agent or process, the treatment must suppress L. monocytogenes growth during a product's shelf life to $\leq 2 \log$ cycles. Less frequent USDA sampling will likely occur if the agent or process restricts growth to $\leq 1$ log cycle. Based upon initial reductions on frankfurter surfaces achieved in the current study and on limited outgrowth observed over 42 days of refrigerated storage, a single surface application of a $1 \%$ CPC spray meets both alternative 1 and 2 criteria for L. monocytogenes control. 
FIGURE 3. Total aerobic plate counts on frankfurters either not treated (control) or treated with cetylpyridinium chloride $11 \%$ spray at $20 \mathrm{psi}, 25^{\circ} \mathrm{C}$, and 30-s exposure time) and stored vacuum packaged for 42 days at 0 and $4^{\circ} \mathrm{C}$. control $0^{\circ} \mathrm{C}$; control $4{ }^{\circ} \mathrm{C} ; \bigcirc$, treatment $0^{\circ} \mathrm{C} ; \square$, treatment $4^{\circ} \mathrm{C}$. Error bars indicate standard deviation of the mean of three replicates.

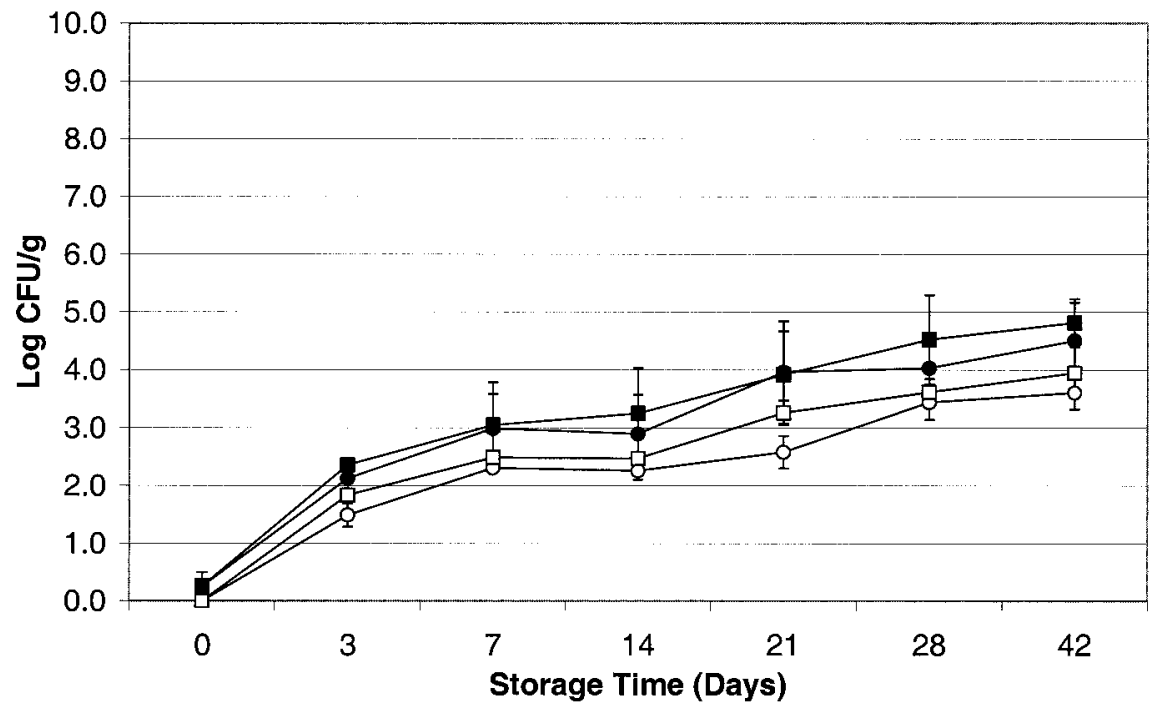

Effects of 1\% CPC on naturally occurring bacterial populations on frankfurters. CPC treatment and storage time had a significant effect $(P \leq 0.05)$ on the aerobic bacterial and LAB populations of frankfurters regardless of storage temperature. After 42 days of storage at 0 and $4^{\circ} \mathrm{C}$, APCs of CPC-treated samples increased to $4 \log \mathrm{CFU} / \mathrm{g}$ from initially undetectable levels (detection limit, $<2 \mathrm{CFU} /$ $\mathrm{g}$ ), whereas APCs of nontreated (control) samples reached approximately $5 \log \mathrm{CFU} / \mathrm{g}$ (Fig. 3). Within each treatment, no significant differences $(P>0.05)$ were observed in the APCs of samples stored at 0 versus $4^{\circ} \mathrm{C}$. Similar trends were observed for LAB populations (data not shown), with populations of $3.2 \log \mathrm{CFU} / \mathrm{g}$ observed after 42 days of storage compared with undetectable levels (detection limit, $<2 \log \mathrm{CFU} / \mathrm{g}$ ) immediately posttreatment. For YM populations, only very low concentrations were observed toward the end of storage (data not shown); CPC treatment appeared to delay slightly the outgrowth of YM populations as compared with nontreated samples. Neither coliform nor E. coli populations were detected (detection limit, $<2$ CFU/ g) in any samples analyzed (treated or nontreated).

Effects of 1\% CPC on color of frankfurters. Color data were collected on samples stored at 0 and $4^{\circ} \mathrm{C}$ over a 42 -day storage interval to determine whether $1 \% \mathrm{CPC}$ treat- ment influenced L* (lightness), a* (redness), and $\mathrm{b}^{*}$ (yellowness) values. Samples stored at $0^{\circ} \mathrm{C}$ were held in a walkin cooler in the absence of light, and those stored at $4^{\circ} \mathrm{C}$ were held in simulated retail display lighting. CPC treatment did not significantly affect $(P>0.05)$ the color of frankfurters stored at $0^{\circ} \mathrm{C}$ for 42 days (data not shown). For nontreated frankfurters and those treated with $1 \% \mathrm{CPC}, \mathrm{L}^{*}$ values were 47.43 to 49.63 and 47.63 to 50.17 , respectively, $\mathrm{a}^{*}$ values were 12.73 to 13.5 and 12.5 to 16 , respectively, and $b^{*}$ values were 13.87 to 16.20 and 13.63 to 16.53 , respectively.

For samples stored at $4^{\circ} \mathrm{C}$ (Table 1), no significant differences $(P>0.05)$ in $\mathrm{L}^{*}$ and $\mathrm{a}^{*}$ values were observed. The $b^{*}$ values were 14.93 to 16.07 for nontreated frankfurters and 15.33 to 16.07 for frankfurters treated with $1 \%$ $\mathrm{CPC}$ and stored at $4^{\circ} \mathrm{C}$ (Table 1). The ANOVA of $\mathrm{b}^{*}$ values indicated a significant difference $(P \leq 0.05)$ in the yellowness of treated and nontreated frankfurters on days 14 and 28 at $4^{\circ} \mathrm{C}$ (Table 1); however, no particular trend was observed for the subsequent sampling time (day 42). Other researchers also have found that surface treatment of frankfurters with antimicrobial solutions such as organic acids, acidified calcium sulfate, and potassium lactate had negligible effects on product color and overall acceptability ( 1 ,

TABLE 1. Lightness $\left(L^{*}\right)$, redness $\left(a^{*}\right)$, and yellowness $\left(b^{*}\right)$ of frankfurters either not treated (control) or treated with cetylpyridinium chloride (1\% CPC spray at $20 \mathrm{psi}, 25^{\circ} \mathrm{C}$, and 30 -s exposure time) and stored vacuum packaged at $4{ }^{\circ} \mathrm{C}$ for 42 days with simulated retail display lighting ${ }^{a}$

\begin{tabular}{|c|c|c|c|c|c|c|}
\hline Days & \multicolumn{2}{|c|}{$\mathrm{L}^{*}$} & \multicolumn{2}{|c|}{$a^{*}$} & \multicolumn{2}{|c|}{$b^{*}$} \\
\hline 3 & $48.13 \pm 0.12$ & $48.43 \pm 0.59$ & $12.93 \pm 0.67$ & $13.67 \pm 1.15$ & $15.13 \pm 0.21$ & $15.33 \pm 0.45$ \\
\hline 7 & $47.50 \pm 0.53$ & $48.07 \pm 0.45$ & $13.50 \pm 0.10$ & $13.33 \pm 2.00$ & $15.30 \pm 0.20$ & $15.33 \pm 0.29$ \\
\hline 14 & $48.73 \pm 0.70$ & $48.70 \pm 1.30$ & $13.10 \pm 0.60$ & $13.13 \pm 0.85$ & $14.93 \pm 0.35$ & $15.97 \pm 1.07$ \\
\hline 42 & $49.63 \pm 1.14$ & $49.33 \pm 1.66$ & $13.40 \pm 1.00$ & $14.00 \pm 1.47$ & $16.07 \pm 0.25$ & $16.07 \pm 0.49$ \\
\hline
\end{tabular}

${ }^{a}$ Values are mean \pm standard deviation. Least significant differences were 0.32 for $\mathrm{L}^{*}, 0.74$ for $\mathrm{a}^{*}$, and 0.50 for $\mathrm{b}^{*}$. 
11, 13, 18). Singh et al. (22) reported that surface treatment of RTE polish sausages with $1 \%$ CPC resulted in no practically significant adverse effects on color. Other researchers have reported no negative effect and perhaps even a beneficial effect of CPC on the color of ground beef produced from CPC-treated beef trim $(14,20)$.

Although not noted in the current study, storage temperature and lighting conditions within the $4^{\circ} \mathrm{C}$ display case may cause deterioration in redness. The lighted display and the $1 \%$ CPC treatment did not have a synergistically negative effect on the color of frankfurters during storage at $4^{\circ} \mathrm{C}$. Processors should be aware that packaging and processing variation may contribute to differences in color values. Kropf (17) suggested that microbial contamination of comminuted meat may result in discoloration.

Effect of 1\% CPC on firmness of frankfurters. Samples stored at both 0 and $4^{\circ} \mathrm{C}$ were evaluated for firmness. Firmness values ranged from approximately 2,500 to 2,900 $g$ force (data not shown). These values are similar to those observed by Choi and Chin (9) for comminuted sausages. The analysis suggested that significant differences $(P \leq$ 0.05 ) among days within the same total storage time existed. However, there was no apparent trend or pattern associated with these differences. The differences observed may be attributed to processing variation rather than to treatment effects. Our results are similar to those of Lu et al. (18), who reported an effect of storage time on the peak force (surface puncture) of the frankfurters but considered the effect a statistical anomaly rather than a true difference due to treatment. Other researchers (8) reported that treating the surface of frankfurters with pediocin did not impact textural characteristics of the products.

Application of a 1\% CPC surface spray to frankfurters immediately prior to packaging reduced L. monocytogenes concentrations by 1.4 to $1.7 \mathrm{log} \mathrm{CFU} / \mathrm{g}$ and restricted growth of the pathogen during 42 days of refrigerated storage compared with that in nontreated samples, thereby meeting USDA alternative 1 and 2 criteria for Listeria control. The $1 \%$ CPC treatment resulted in only minor influences on color ( $b^{*}$ values) and firmness. Additional research is warranted to evaluate various CPC concentrations, $\mathrm{CPC}$ residuals on food surfaces, and subsequent organoleptic effects. Further evaluation of the impacts of CPC treatment on sensory characteristics (e.g., taste) is warranted and is most appropriately evaluated on a product-by-product basis. Other areas for further investigation include the performance of CPC treatments when RTE products are stored at abusive temperatures and evaluation of the effectiveness of CPC treatments when applied before rather than after introduction of L. monocytogenes onto RTE products.

\section{ACKNOWLEDGMENTS}

Support was provided by the Cooperative State Research, Extension and Education Service, USDA, under agreement 93-34211-8362, Food Safety Consortium and by the American Meat Institute Foundation.

\section{REFERENCES}

1. Barmpalia, I. M., I. Geornaras, K. E. Belk, J. A. Scanga, P. A. Kendall, G. C. Smith, and J. N. Sofos. 2004. Control of Listeria mon- ocytogenes on frankfurters with antimicrobials in the formulation and by dipping in organic acid solutions. J. Food Prot. 67:24562464.

2. Borchert, L. L. 1999. Technology forum: Listeria monocytogenes interventions for ready-to-eat meat products. American Meat Institute, Washington, D.C.

3. Breen, P. J., C. M. Compadre, E. K. Fifer, H. Salari, D. C. Serbus, and D. L. Lattin. 1995. Quaternary ammonium compounds inhibit and reduce the attachment of viable Salmonella typhimurium to poultry tissues. J. Food Sci. 60:1191-1196.

4. Breen, P. J., H. Salari, and C. M. Compadre. 1997. Elimination of Salmonella contamination from poultry tissues by cetylpyridinium chloride solutions. J. Food Prot. 60:1019-1021.

5. Centers for Disease Control and Prevention. 1997. Foodborne diseases active surveillance network, 1996. Morb. Mortal. Wkly. Rep. 46:258-261.

6. Centers for Disease Control and Prevention. 1998. Multistate outbreak of listeriosis-United States, 1998. Morb. Mortal. Wkly. Rep. 47:1085-1086.

7. Centers for Disease Control and Prevention. 2002. Public health dispatch: outbreak of listeriosis-northeastern United States, 2002. Morb. Mortal. Wkly. Rep. 51:950-951.

8. Chen, C. M., J. G. Sebranek, J. S. Dickson, and A. F. Mendonca. 2004. Use of pediocin (ALTA 2341) for control of Listeria monocytogenes on frankfurters. J. Muscle Foods 15:35-56.

9. Choi, S. H., and K. B. Chin. 2003. Evaluation of sodium lactate as a replacement for conventional chemical preservatives in comminuted sausages inoculated with Listeria monocytogenes. Meat Sci. 65:531-537.

10. Cutter, C. N., W. J. Dorsa, A. Handie, S. Rodriguez-Morales, X. Zhou, P. J. Breen, and C. M. Compadre. 2000. Antimicrobial activity of cetylpyridinium chloride washes against pathogenic bacteria on beef surfaces. J. Food Prot. 63:593-600.

11. De Gonzalez, M. T. N., J. T. Keeton, and L. J. Ringer. 2004. Sensory and physicochemical characteristics of frankfurters containing lactate with antimicrobial surface treatments J. Food Sci. 69:S221-S228.

12. Glass, K. A., and M. P. Doyle. 1989. Fate of Listeria monocytogenes in processed meat products during refrigerated storage. Appl. Environ. Microbiol. 55:1565-1569.

13. Islam, M., J. Chen, M. P. Doyle, and M. Chinnan. 2002. Control of Listeria monocytogenes on turkey frankfurters by generally recognized as safe preservatives. J. Food Prot. 65:1411-1416.

14. Jimenez-Villarreal, J. R., F. W. Pohlman, Z. B. Johnson, A. H. Brown, Jr., and R. T. Baublits. 2003. The impact of single antimicrobial intervention treatment with cetylpyridinium chloride, trisodium phosphate, chlorine dioxide or lactic acid on ground beef lipid, instrumental color and sensory characteristics. Meat Sci. 65:977984.

15. Johnson, J. L., M. P. Doyle, and R. G. Cassens. 1990. Listeria monocytogenes and other Listeria spp. in meat and meat products: a review. J. Food Prot. 53:81-91.

16. Johnson, J. L., M. P. Doyle, and R. G. Cassens. 1990. Incidence of Listeria spp. in retail meat roasts. J. Food Sci. 55:572-574.

17. Kropf, D. H. 1980. Effects of retail display conditions on meat color, p. 15-32. In Proceedings of the 33rd Annual Reciprocal Meat Conference. American Meat Science Association, Savoy, Ill.

18. Lu, Z., J. G. Sebranek, J. S. Dickson, A. F. Mendonca, and T. B. Bailey. 2005. The effects of organic acid salt solutions on sensory and other quality characteristics of frankfurters. J. Food Sci. 70: S123-S127.

19. Palumbo, S. A., and A. C. Williams. 1994. Control of Listeria monocytogenes on surface of frankfurters by acid treatments. Food Microbiol. 11:293-300.

20. Pohlman, F. W., M. R. Stivarius, K. S. McElyea, Z. B. Johnson, and M. G. Johnson. 2002. The effects of ozone, chlorine dioxide, cetylpyridinium chloride and trisodium phosphate as multiple antimicrobial interventions on microbiological, instrumental color, and sensory color and odor characteristics of ground beef. Meat Sci. 61: 307-313.

21. Schwartz, B., C. A. Ciesielski, C. V. Broome, S. Gaventa, G. R. 
Brown, B. G. Gellin, A. W. Hightower, and L. Mascola. 1988. Association of sporadic listeriosis with consumption of uncooked hotdogs and undercooked chicken. Lancet ii(8614):779-782.

22. Singh, M., V. S. Gill, H. Thippareddi, R. K. Phebus, J. L. Marsden, T. J. Herald, and A. L. Nutsch. Cetylpyridinium chloride treatment of ready-to-eat polish sausages: effects on Listeria monocytogenes populations and quality attributes. Foodborne Pathog. Dis., in press.

23. Uhart, M., S. Ravishankar, and N. D. Maks. 2004. Control of Listeria monocytogenes with combined antimicrobials on beef franks stored at $4^{\circ}$ C. J. Food Prot. 67:2296-2301.

24. U.S. Department of Agriculture, Food Safety and Inspection Service. 2002. Microbial sampling of ready to eat (RTE) products for the FSIS verification testing program. FSIS directive 10240.3. U.S. Department of Agriculture, Food Safety and Inspection Service, Washington, D.C.

25. U.S. Department of Agriculture, Food Safety and Inspection Service. 2003. Control of Listeria monocytogenes in ready-to-eat meat and poultry products, interim final rule. Fed. Regist. 68:34208-34254.

26. U.S. Department of Agriculture, Food Safety and Inspection Service. 2004. Use of food ingredients and sources of radiation. 9 CFR 424.21. U.S. Department of Agriculture, Food Safety and Inspection Service, Washington, D.C.

27. U.S. Department of Agriculture, Food Safety and Inspection Service. 2004. Safe and suitable ingredients used in the production of meat and poultry products. FSIS directive 7120.1, amendment 2. Available at: http://www.fsis.usda.gov/OPPDE/rdad/FSISDirectives/7120. 1Amend2.pdf. Accessed 15 December 2004.
28. U.S. Department of Agriculture, Food Safety and Inspection Service. 2004. Compliance guidelines to control Listeria monocytogenes in post-lethality exposed ready-to-eat meat and poultry products. Available at: http://www.fsis.usda.gov/OPPDE/rdad/FRPubs/97-013F/ Lm_Rule_Compliance_Guidelines_2004.pdf. Accessed 15 December 2004.

29. U.S. Food and Drug Administration. 1998. Detection and enumeration of Listeria monocytogenes in foods, chap. 10. In Bacteriological analytical manual, 8th ed., rev. A. AOAC International, Gaithersburg, Md.

30. U.S. Food and Drug Administration. 2003. Quantitative assessment of the relative risk to public health from foodborne Listeria monocytogenes among selected categories of ready-to-eat foods. U.S. Food and Drug Administration Center for Food Safety and Applied Nutrition, College Park, Md.

31. U.S. Food and Drug Administration. 2004. Final rule: secondary direct food additives permitted in food for human consumption. Fed. Regist. 69:17297-17298.

32. Wang, H., Y. Li, and M. F. Slavik. 2001. Efficacy of cetylpyridinium chloride in immersion treatment for reducing populations of pathogenic bacteria on fresh-cut vegetables. J. Food Prot. 64:2071-2074.

33. Wang, W. C., Y. Li, M. F. Slavik, and H. Xiong. 1997. Trisodium phosphate and cetylpyridinium chloride spraying on chicken skin to reduce attached Salmonella typhimurium. J. Food Prot. 60:992-994.

34. Xiong, H., Y. Li, M. F. Slavik, and T. J. Walker. 1998. Spraying chicken with selected chemicals to reduce attached Salmonella typhimurium. J. Food Prot. 61:272-275. 